\title{
Efeito da temperatura e da luz na germinação de sementes de Acacia polyphylla DC.
}

\author{
JOÃO C. ARAÚJO NETO ${ }^{1,3}$, IVOR B. AGUIAR² e VILMA M. FERREIRA ${ }^{1}$
}

(recebido: 14 de janeiro de 2001; aceito: 9 de abril de 2003)

\begin{abstract}
Effect of temperature and light on Acacia polyphylla DC. seed germination). Acacia polyphylla (LeguminosaeMimosoideae) is a typical tree species of secondary succession in Brazil, important for restoration of degraded areas. The purpose of this work was to evaluate the seed germination under different temperatures and light conditions. Constant $(15,20$, 25 and $\left.30^{\circ} \mathrm{C}\right)$ and alternating $\left(20-30^{\circ} \mathrm{C}\right)$ temperatures were evaluated, at an eight hours photoperiod under white light. Constant temperature of $25^{\circ} \mathrm{C}$ was optimal and the light experiments were conducted at that temperature. Seeds were incubated in darkness and at photoperiods from 1 to 12 hours under white light (high red/far-red ratio), as well as at photoperiods under white light initiated and concluded with shade light (low red/far-red ratio). Germination percentage was not affected by the photoperiods under white light tested, but a photoperiod similar or higher than four hours was required for better initial seedling growth. Both germination percentage and speed was not affected by light of a low red/far-red ratio, but they decreased in darkness.
\end{abstract}

Key words - Acacia polyphylla, germination, light, phytochrome, temperature

RESUMO - (Efeito da temperatura e da luz na germinação de sementes de Acacia polyphylla DC.). Acacia polyphylla é uma espécie arbórea característica dos estádios iniciais da sucessão secundária, de grande utilidade na recuperação de áreas degradadas. O presente trabalho teve como objetivo estudar a germinação de suas sementes sob diferentes condições de temperatura e luz. Avaliaram-se os efeitos das temperaturas constantes de $15,20,25$ e $30^{\circ} \mathrm{C}$ e alternada de $20-30{ }^{\circ} \mathrm{C}$, sob fotoperíodo de oito horas de luz branca. A temperatura constante de $25^{\circ} \mathrm{C}$ foi a mais adequada para a germinação e o estudo de luz foi realizado nessa temperatura. As sementes foram submetidas à ausência de luz e a fotoperíodos de 1 a 12 horas sob luz branca (alta relação vermelho/vermelho-extremo), além de fotoperíodos sob luz branca iniciados e finalizados com luz de sombreamento (baixa relação vermelho/vermelho-extremo). A porcentagem de germinação não foi afetada pelos diferentes fotoperíodos sob luz branca testados, mas fotoperíodo igual ou superior a quatro horas favoreceu o desenvolvimento inicial das plântulas. A germinação não foi afetada pela luz com baixa relação vermelho/vermelho-extremo, mas na ausência de luz as sementes germinaram em menores porcentagem e velocidade.

Palavras-chave - Acacia polyphylla, fitocromo, germinação, luz, temperatura

\section{Introdução}

Nos últimos anos tem se intensificado o interesse na propagação de espécies florestais nativas, devido à ênfase atual nos problemas ambientais, ressaltando-se a necessidade de recuperação de áreas degradadas e recomposição da paisagem. Entretanto, não há conhecimento disponível para o manejo e análise das sementes da maioria dessas espécies, de modo a fornecer dados que possam caracterizar seus atributos físicos e fisiológicos. Há, também, necessidade de se obterem informações básicas sobre a germinação, cultivo e potencialidade dessas espécies nativas, visando sua utilização para os mais diversos fins.

\footnotetext{
1. Universidade Federal de Alagoas, Centro de Ciências Agrárias. BR 104-Norte, Km 85, 57100-000 Rio Largo, AL, Brasil.

2. Universidade Estadual Paulista, Faculdade de Ciências Agrárias e Veterinárias. Via de acesso Prof. Paulo Donato Castellane, 14884-900 Jaboticabal, SP, Brasil.

3._Autor para correspondência: jcanetto@bol.com.br
}

Com relação às espécies tropicais, Leal Filho \& Borges (1992) salientaram que muito pouco se conhece sobre as exigências das sementes quanto aos efeitos da temperatura e da luz para a germinação, principalmente para as espécies típicas de vegetação secundária.

Enfocando a germinação como resultado de uma série de reações bioquímicas, observa-se a existência de estreita dependência da temperatura. Como em qualquer reação química, existe uma temperatura ótima na qual o processo se realiza mais rápida e eficientemente, variável entre as diferentes espécies (Bewley \& Black 1982).

A temperatura adequada para a germinação de sementes de espécies arbóreas nativas vem sendo determinada por alguns pesquisadores. Como exemplo, foram definidas como ótimas para a germinação, a temperatura de $25{ }^{\circ} \mathrm{C}$ para sementes de Stevia rebaudiana Bert. (Randi \& Felippe 1981), as de 30 e $35{ }^{\circ} \mathrm{C}$ para sementes de Prosopis juliflora (Sw.) DC. (Perez \& Moraes 1990), e as de 25 e $30^{\circ} \mathrm{C}$ para 
sementes de Mabea fistulifera Mart. (Leal Filho \& Borges 1992).

No tocante ao comportamento germinativo de espécies sensíveis à luz, encontram-se sementes que germinam somente após rápida exposição à luz, outras que necessitam de período amplo de exposição, outras em que a germinação é desencadeada somente no escuro (Vidaver 1980) e sementes indiferentes à luz (VázquezYanes \& Orozco-Segovia 1991).

Segundo Vidaver (1980), Bryant (1985) e VázquezYanes \& Orozco-Segovia (1990), o fitocromo é o pigmento receptor responsável pela captação de sinais luminosos que podem ou não desencadear a germinação das sementes. O modo de ação desse pigmento depende do tipo de radiação incidente, pois luz com alta relação vermelho/vermelho-extremo (V/VE) pode induzi-lo a assumir a forma ativa (FVe), promovendo a germinação de sementes fotossensíveis, enquanto luz com baixa relação V/VE pode levá-lo a assumir a forma inativa (FV), impedido a germinação.

As respostas das sementes à influência do fitocromo foram discutidas por Lagôa \& Pereira (1987), Taiz \& Zeiger (1998), Casal \& Sánchez (1998) e Casal et al. (1998), dentre outros. Segundo esses autores, as fotorrespostas podem ser comumente divididas em três categorias, baseadas na exigência de luz em termos de fluência (quantidade de fótons que chega em uma dada área em um determinado tempo).

Assim, há respostas de fluência baixa (RFB), com indução por luz vermelha, podendo ser revertida por luz vermelha-extrema, neste caso, a irradiação final determinará a resposta. As respostas de fluência muito baixa (RFMB) são induzidas por baixas fluências de luz, como por exemplo entre $10^{-4}$ e $10^{-2} \mu \mathrm{mol} \mathrm{m}{ }^{-2} \mathrm{de}$ luz vermelha, não sendo, portanto, reversíveis por vermelho-extremo, ao contrário, este comprimento de onda também induz a germinação das sementes. Para Pons (1993) e Casal et al. (1998), esse tipo de resposta é extremamente sensível à forma ativa do fitocromo e à exposição ao comprimento de onda longo (VE). Neste caso, mesmo a luz na faixa do verde, utilizada nas contagens das sementes germinadas, pode desencadear o processo germinativo. Com relação às respostas de alta irradiância (RIA), há necessidade de longa exposição à luz na faixa do vermelho-extremo ou azul, não ocorrendo fotorreversibilidade V/VE. Essa resposta, segundo Mancinelli (1994), é dependente da irradiação e requer a excitação contínua de FV e FVe.

A espécie utilizada neste trabalho pertence à família Leguminosae, subfamília Mimosoideae, e é conhecida popularmente como "monjoleiro" ou "paricá-branco"
(Lorenzi 1992). É uma árvore semidecídua, heliófita, característica de formações secundárias, ocorrendo desde a região Amazônica até o Estado do Paraná, sendo particularmente freqüente nos Estados de Minas Gerais e de São Paulo. Apresenta características de rápido crescimento e rusticidade, além de propriedades ornamentais que a qualificam para arborização de parques e jardins. Possui grande utilidade em reflorestamentos heterogêneos destinados à preservação permanente de áreas não cultivadas e solos recémrevolvidos (Corrêa 1978, Lorenzi 1992).

Apesar desse potencial, são escassas as informações sobre os fatores que afetam a germinação de suas sementes, bem como informações ecofisiológicas para a espécie. Assim, o presente trabalho teve como objetivo estudar os efeitos dos fatores temperatura e luz na germinação das sementes de monjoleiro.

\section{Material e métodos}

Frutos maduros de Acacia polyphylla (monjoleiro), apresentando aspecto seco e início de deiscência, foram colhidos de 10 árvores pertencentes a dois fragmentos florestais localizados no município de Jaboticabal, SP. Esse município está situado a $21^{\circ} 16^{\prime} \mathrm{S}$ e $48^{\circ} 19^{\prime} \mathrm{W}$ e a 575 metros de altitude. Segundo a classificação climática de Köppen, o clima é de transição entre os tipos Cwa (quente de inverno seco) e Aw (tropical de inverno seco), de acordo com Ventura et al. (1965/1966).

As atividades experimentais foram conduzidas no laboratório de sementes do Departamento de Produção Vegetal da Faculdade de Ciências Agrárias e Veterinárias (FCAV), pertencente à Universidade Estadual Paulista (UNESP), Campus de Jaboticabal, SP. Após a colheita, os frutos foram secos ao ar, em local sombreado, por sete dias, para completarem sua deiscência e facilitar a extração das sementes.

Por ocasião de cada experimento, realizou-se uma seleção manual para a eliminação de sementes chochas e atacadas por insetos e, em seguida, as amostras foram homogeneizadas em divisor de solo. $\mathrm{O}$ teor de água das sementes foi de $10,3 \%$, determinado pelo método de estufa a $105^{\circ} \mathrm{C}$, descrito nas Regras para Análise de Sementes (Brasil 1992).

A assepsia das sementes foi realizada mediante a imersão em soluções de hipoclorito de sódio $2 \%$ (v/v) por 10 minutos e de álcool $70 \%(\mathrm{v} / \mathrm{v})$ por 1 minuto, após cada tratamento as sementes foram lavadas em água destilada. Para a condução dos testes de germinação, as sementes foram colocadas em caixas plásticas de $11 \times 11 \times 4 \mathrm{~cm}$, sobre duas folhas de papel de filtro previamente umedecidas com água destilada.

Para o estudo da temperatura, foi utilizado um lote de 
sementes colhido em setembro de 2000 . Foram testadas as temperaturas constantes de $15,20,25$ e $30^{\circ} \mathrm{C}$ e a temperatura alternada de $20-30^{\circ} \mathrm{C}$. O fotoperíodo adotado foi de oito horas de luz branca, fornecida por 10 lâmpadas fluorescentes tipo "luz do dia" de 15 w. No caso da temperatura alternada, o período luminoso coincidiu com a temperatura mais elevada.

Para avaliar o efeito da luz na germinação foram realizados dois experimentos, com sementes colhidas em outubro de 2000, as quais foram mantidas em germinadores regulados para a temperatura constante de $25^{\circ} \mathrm{C}$. No primeiro experimento foram estudados os fotoperíodos de $0,1,2,4,6,8,10$ e 12 horas, sob luz branca.

No segundo experimento, as sementes foram incubadas sob luz de diferentes qualidades espectrais, sendo os fotoperíodos iniciados e finalizados com luz de sombreamento que corresponde, na natureza, à luz filtrada pelo dossel. Os tratamentos testados foram: $\left(\mathrm{T}_{1}\right) 2$ horas de luz de sombreamento +8 horas de luz branca +2 horas de luz de sombreamento; $\left(\mathrm{T}_{2}\right) 3$ horas de luz de sombreamento +6 horas de luz branca +3 horas de luz de sombreamento; $\left(\mathrm{T}_{3}\right) 4$ horas de luz de sombreamento +4 horas de luz branca +4 horas de luz de sombreamento; $\left(\mathrm{T}_{4}\right) 5$ horas de luz de sombreamento +2 horas de luz branca +5 horas de luz de sombreamento; $\left(\mathrm{T}_{5}\right) 15$ minutos de vermelho-extremo +12 horas de luz branca +15 minutos de vermelho-extremo; $\left(\mathrm{T}_{6}\right)$ ausência de luz, com contagem de sementes germinadas apenas no final do teste.

Neste experimento, a razão V/VE da luz de sombreamento foi de 0,077 e o fotoequilíbrio do fitocromo $(\varphi)$, calculado de acordo com Mancinelli (1994), foi de 0,18. A luz de sombreamento foi obtida segundo o procedimento adotado por Leite (1998). Foram utilizadas quatro lâmpadas incandescentes de $25 \mathrm{w}$ cada, colocadas dentro de uma caixa de madeira, a qual foi presa, pela face superior, em uma das prateleiras do germinador. A face oposta era constituída de duas placas de acrílico, uma vermelha e outra azul, fornecendo luz vermelha-extrema. No lado externo dessa face foi presa uma lâmpada fluorescente de $15 \mathrm{w}$, que forneceu luz branca. Foram utilizados dois "timers" para monitoramento do período luminoso, um para cada qualidade espectral. Para fornecer luz vermelha-extrema, no tratamento $\mathrm{T}_{5}$, apenas as lâmpadas incandescentes permaneceram ligadas por 15 minutos.

Como medida de segurança, para evitar que ocorresse um "lampejo" de luz branca ao final do período de iluminação, que poderia reverter o efeito da luz vermelha-extrema, as lâmpadas incandescentes eram desligadas 20 minutos após o desligamento das lâmpadas fluorescentes.

Em todos os experimentos, foram utilizadas caixas plásticas transparentes, para os tratamentos que receberam luz, e caixas plásticas de coloração preta para os tratamentos referentes à ausência de luz. Nos dois experimentos de luz, com exceção do tratamento $\mathrm{T}_{6}$ do segundo experimento, as avaliações foram realizadas sob luz na faixa do verde.
Consideraram-se germinadas as sementes que originaram plântulas normais, com todas as suas estruturas essenciais convenientemente desenvolvidas (Labouriau 1983, Brasil 1992). As contagens das sementes germinadas foram efetuadas diariamente, durante o período de trinta dias, procedendo-se ao reumedecimento do substrato com água destilada, quando necessário.

Os resultados dos testes de germinação foram expressos em porcentagem final, tempo médio e freqüência relativa diária de germinação, obtidos mediante as fórmulas propostas por Labouriau \& Valadares (1976). Foi também calculado o índice de velocidade de germinação, adotando-se a fórmula de Maguire, descrita por Nakagawa (1994).

Foi utilizado o delineamento experimental inteiramente casualizado, com quatro repetições de 50 sementes no experimento de tempertura e de 25 sementes nos experimentos de luz. Os resultados foram submetidos à análise de variância e as médias comparadas pelo teste de Tukey, ao nível de 5\% de probabilidade. Para efeito da análise de variância, os dados de porcentagem de germinação foram transformados em $\operatorname{arcsen} \sqrt{\% / 100}$ (Banzatto \& Kronka 1992), porém, foram apresentados nas tabelas como valores originais.

\section{Resultados e Discussão}

De acordo com os resultados apresentados na tabela 1 , verifica-se que a temperatura de $15{ }^{\circ} \mathrm{C}$ prejudicou o desempenho germinativo das sementes de Acacia polyphylla. Nessa temperatura observou-se, durante a contagem das sementes germinadas, que o crescimento da raiz primária das plântulas não foi estimulado e, ao final do teste, as sementes não germinadas encontravam-se com sinais evidentes de deterioração. A germinação praticamente nula, constatada nessa tempertura, está de acordo com observação de Okusanya $(1978,1980)$, quanto ao fato de que as sementes de muitas espécies tropicais são sensíveis à baixa temperatura, apresentando geralmente limite inferior acima de $5{ }^{\circ} \mathrm{C}$.

Observou-se aumento da porcentagem de germinação com o aumento da temperatura até $25^{\circ} \mathrm{C}$, tendendo a decrescer a partir dessa temperatura. A $20{ }^{\circ} \mathrm{C}$ a porcentagem e a velocidade de germinação foram menores que a $25{ }^{\circ} \mathrm{C}$, resultando, também, em maior tempo médio de germinação. Durante as contagens de sementes germinadas a $30{ }^{\circ} \mathrm{C}$, algumas plântulas apresentaram inibição no crescimento da parte aérea, resultando em atraso no processo germinativo. Assim, a temperatura constante de $25{ }^{\circ} \mathrm{C}$ foi a mais adequada para a germinação das sementes de monjoleiro.

Conforme Bewley \& Black (1985), a temperatura afeta tanto a capacidade como a velocidade de 
Tabela 1. Porcentagem (PG), índice de velocidade (IVG) e tempo médio (TMG) de germinação de sementes de Acacia polyphylla (monjoleiro) submetidas a diferentes temperaturas, sob fotoperíodo de oito horas de luz branca. Médias seguidas de mesma letra, em cada coluna, não diferem entre si pelo teste de Tukey, a 5\% de probabilidade.

Table 1. Germination percentage (PG), speed index (IVG) and mean germination time (TMG) of Acacia polyphylla ("monjoleiro") seeds submitted to different temperatures, at photoperiod of eight hours of white light. Means for each column followed by same letter are not significantly different $(\mathrm{P}>0.05)$.

\begin{tabular}{cccl}
\hline $\begin{array}{c}\text { Temperatura } \\
\left({ }^{\circ} \mathrm{C}\right)\end{array}$ & $\begin{array}{c}\text { PG } \\
(\%)\end{array}$ & IVG & $\begin{array}{l}\text { TMG } \\
(\text { dias })\end{array}$ \\
\hline 15 & $0,6 \mathrm{c}$ & $0,5 \mathrm{c}$ & $19,3 \mathrm{a}$ \\
20 & $24,5 \mathrm{~b}$ & $0,9 \mathrm{c}$ & $15,0 \mathrm{~b}$ \\
25 & $51,0 \mathrm{a}$ & $2,9 \mathrm{a}$ & $10,6 \mathrm{c}$ \\
30 & $46,3 \mathrm{a}$ & $2,1 \mathrm{ab}$ & $12,3 \mathrm{bc}$ \\
$20-30$ & $45,6 \mathrm{a}$ & $1,6 \mathrm{bc}$ & $15,3 \mathrm{~b}$ \\
C.V. $(\%)$ & 21,1 & 30,5 & 10,1 \\
\hline
\end{tabular}

germinação. As sementes têm a capacidade de germinar dentro de uma determinada faixa de temperatura, característica para cada espécie, mas o tempo necessário para se obter a porcentagem máxima de germinação é dependente da temperatura. De acordo com Carvalho \& Nakagawa (1988), temperaturas inferiores ou superiores à ótima tendem a reduzir a velocidade do processo germinativo, expondo as plântulas por maior período a fatores adversos, o que pode levar à redução no total de germinação.

A alternância da temperatura pode proporcionar melhores condições de germinação para sementes de algumas espécies tropicais, como constataram Gomes \& Bruno (1992) para Bixa orellana (L.) e Castellani \& Aguiar (1998) para Trema micrantha (L.) Blume. As sementes que respondem à alternância da temperatura apresentam mecanismos enzimáticos que funcionam em diferentes temperturas (Vázquez-Yanes \& OrozcoSegovia 1987) e, segundo Borges \& Rena (1993), essa resposta corresponde, provavelmente, a uma adaptação às flutuações naturais do ambiente.

Para as sementes de monjoleiro, entretanto, a alternância da temperatura não favoreceu a germinação: os resultados obtidos a $20-30{ }^{\circ} \mathrm{C}$ foram inferiores aos obtidos a $25^{\circ} \mathrm{C}$, principalmente no tocante à velocidade e ao tempo médio de germinação. Melhor comportamento germinativo, em temperatura constante, foi verificado também para sementes de Stevia rebaudiana Bert. (Randi \& Felippe 1981), Urera caracasana (Jacq.) Griseb. (Orozco-Segóvia et al. 1987), Mabea fistulifera Mart. (Leal Filho \& Borges 1992) e Guazuma ulmifolia Lam. (Araújo Neto \& Aguiar 2000).

O melhor comportamento germinativo das sementes de monjoleiro em temperaturas constantes de $30{ }^{\circ} \mathrm{C}$ e, principalmente, $25^{\circ} \mathrm{C}$, pode ser constatado pelos polígonos de freqüência relativa da germinação, apresentados na figura 1. Observa-se que essas temperaturas favoreceram a sincronização da germinação e reduziram seu tempo médio.

$\mathrm{Na}$ tabela 2 encontram-se os dados referentes ao comportamento germinativo das sementes, em função dos diferentes fotoperíodos com luz branca. Constata-se que as sementes de monjoleiro necessitam de luz para expressar sua máxima germinabilidade, uma vez que houve redução considerável na porcentagem e na velocidade de germinação quando as sementes foram incubadas no escuro. Os diferentes fotoperíodos estudados não resultaram em diferenças estatísticas para a porcentagem de germinação. Houve, contudo, efeito da luz no desenvolvimento inicial das plântulas, provavelmente envolvendo processos fotossintéticos. Isso foi evidenciado pela maior velocidade e pelo menor tempo médio de germinação das sementes que receberam luz branca por período igual ou superior a quatro horas.

Pelos gráficos de freqüência relativa diária de germinação, para os diferentes fotoperíodos estudados (figura 2), verifica-se que a germinação das sementes tornou-se mais homogênea na medida em que se aumentou o fotoperíodo. Os fotoperíodos de uma e duas horas determinaram comportamento heterogêneo, semelhante ao apresentado pelas sementes mantidas no escuro.

A capacidade de germinação das sementes de monjoleiro obtida em ampla variação de fotoperíodo sob luz branca, neste experimento, bem como nas temperaturas constante e alternada, no experimento anterior, pode justificar a ocorrência de plântulas dessa espécie em clareiras de diversos tamanhos, em condições naturais.

Em trabalhos desenvolvidos com outras espécies arbóreas, tem-se observado que o número de horas de luz necessário à germinação de sementes fotossensíveis é variável em função da espécie. Assim, há sementes que germinaram após pequenos lampejos de luz, como as de Galinsoga parviflora Cav. (Baroli 1998), e outras que necessitam de períodos mais longos, como as de Miconia cinnamomifolia (DC). Naud., que precisaram 

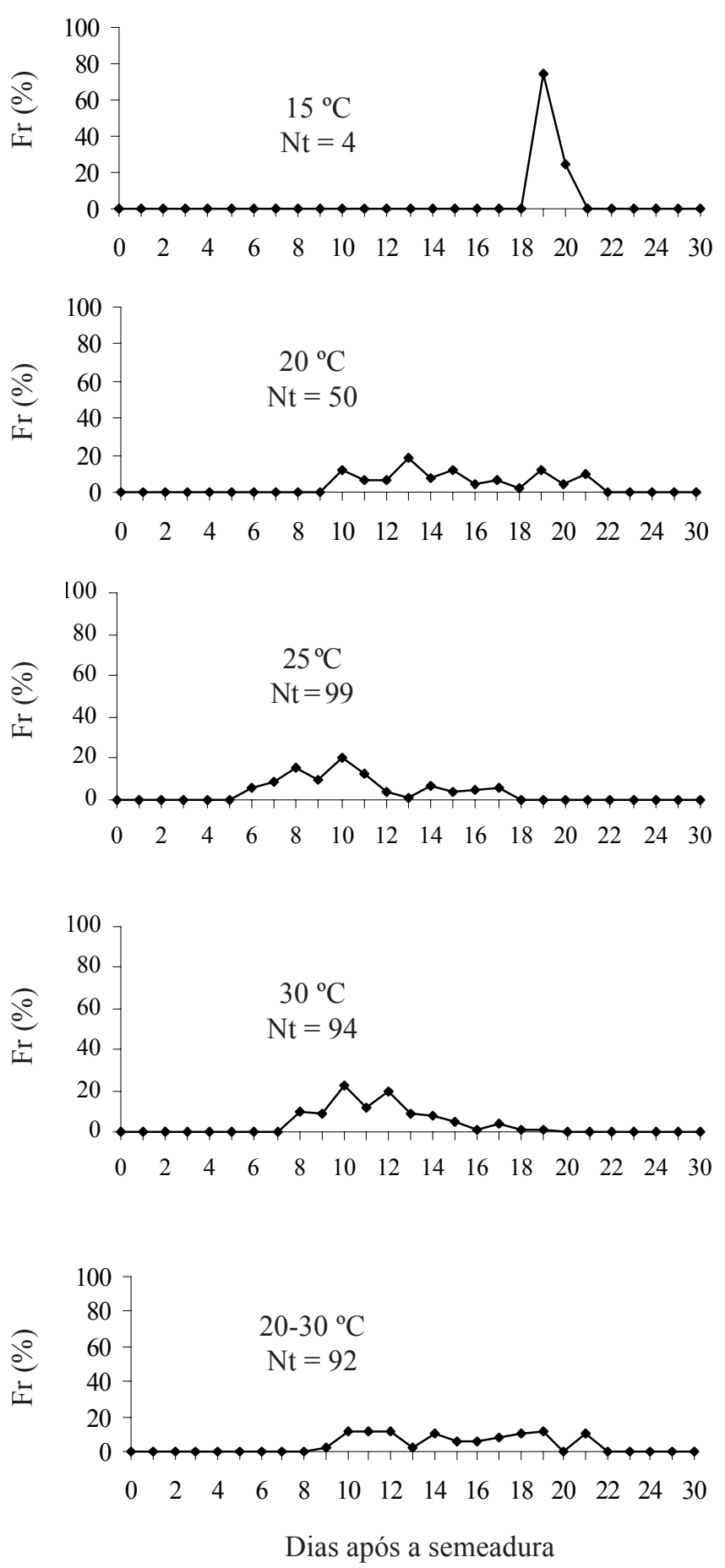

Figura 1. Polígonos de freqüência relativa (Fr) da germinação de sementes de Acacia polyphylla (monjoleiro) submetidas a diferentes temperaturas, sob fotoperíodo de oito horas de luz branca. $\mathrm{Nt}=$ número total de sementes germinadas, em quatro repetições de 50 sementes.

Figure 1. Relative frequency (Fr) of seed germination of Acacia polyphylla ("monjoleiro"), submitted to different temperatures, at photoperiod of eight hours of white light. $\mathrm{Nt}=$ total number of germinated seeds, in four replicates of 50 seeds.
Tabela 2. Porcentagem (PG), índice de velocidade (IVG) e tempo médio (TMG) de germinação de sementes de Acacia polyphylla (monjoleiro) a $25^{\circ} \mathrm{C}$, submetidas a diferentes fotoperíodos de luz branca. Médias seguidas de mesma letra, em cada coluna, não diferem entre si pelo teste de Tukey, a $5 \%$ de probabilidade.

Table 2. Germination percentage (PG), speed index (IVG) and mean germination time (TMG) of Acacia polyphylla ("monjoleiro") seeds at $25^{\circ} \mathrm{C}$, submitted to different photoperiods of white light. Means for each column followed by same letter are not significantly different $(\mathrm{P}>0.05)$.

\begin{tabular}{cccc}
\hline $\begin{array}{c}\text { Fotoperíodo } \\
\text { (horas) }\end{array}$ & $\begin{array}{l}\text { PG } \\
(\%)\end{array}$ & IVG & $\begin{array}{r}\text { TMG } \\
(\text { dias })\end{array}$ \\
\hline 1 & $85,4 \mathrm{a}$ & $1,9 \mathrm{bc}$ & $12,1 \mathrm{~b}$ \\
2 & $91,2 \mathrm{a}$ & $1,7 \mathrm{c}$ & $13,6 \mathrm{~b}$ \\
4 & $90,8 \mathrm{a}$ & $2,5 \mathrm{ab}$ & $9,7 \mathrm{c}$ \\
6 & $86,3 \mathrm{a}$ & $2,7 \mathrm{a}$ & $9,9 \mathrm{c}$ \\
8 & $85,7 \mathrm{a}$ & $2,8 \mathrm{a}$ & $8,3 \mathrm{c}$ \\
10 & $81,3 \mathrm{a}$ & $2,7 \mathrm{a}$ & $8,3 \mathrm{c}$ \\
12 & $84,4 \mathrm{a}$ & $2,8 \mathrm{a}$ & $8,1 \mathrm{c}$ \\
Escuro & $40,8 \mathrm{~b}$ & $0,7 \mathrm{~d}$ & $17,4 \mathrm{a}$ \\
C.V.(\%) & 10,8 & 15,1 & 7,9 \\
\hline
\end{tabular}

de período superior a quatro horas de luz para promover considerável porcentual de germinação (Leite 1998).

Os resultados obtidos com os diferentes fotoperíodos, sequenciados com luz de sombreamento, podem ser visualizados na tabela 3 . Como no experimento anterior, as sementes incubadas no escuro tiveram comportamento germinativo inferior. Não houve diferença estatística entre os demais tratamentos, indicando que a germinação das sementes de monjoleiro não é inibida pela luz com baixa relação vermelho/ vermelho-extremo, nem pelo tempo de exposição à luz.

A porcentagem de germinação constatada em fotoperíodos de luz branca (tabela 2) foi semelhante àquela verificada em fotoperíodos de luz branca seqüenciados com luz de sombreamento (tabela 3 ), indicando que as sementes de monjoleiro podem germinar não apenas em clareiras, como foi mencionado anteriormente, mas também sob dossel de diferentes espessuras.

Conforme Vázquez-Yanes \& Orozco-Segovia (1984), sementes fotoblásticas positivas de espécies que ocorrem freqüentemente em locais degradados, como as invasoras, herbáceas e pioneiras, geralmente não são influenciadas pela intensidade luminosa, mas sim pela qualidade de luz que atinge as sementes. Para as 

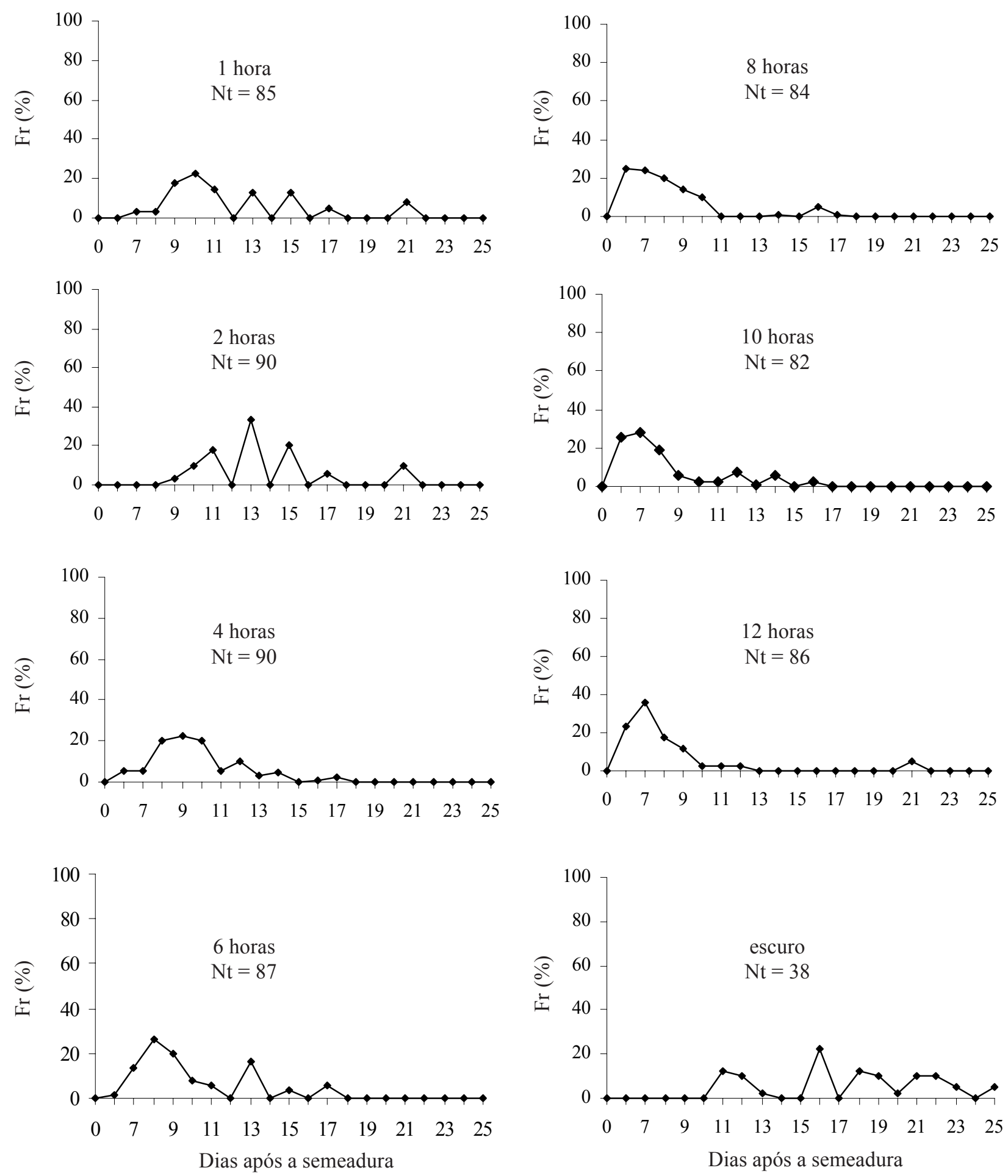

Figura 2. Polígonos de freqüência relativa (Fr) da germinação de sementes de Acacia polyphylla (monjoleiro) a $25^{\circ} \mathrm{C}$, submetidas a diferentes fotoperíodos de luz branca. $\mathrm{Nt}=$ número total de sementes germinadas, em quatro repetições de 25 sementes.

Figure 2. Relative frequency ( $\mathrm{Fr}$ ) of seed germination of Acacia polyphylla ("monjoleiro") at $25{ }^{\circ} \mathrm{C}$, submitted to different photoperiods of white light. $\mathrm{Nt}=$ total number of germinated seeds, in four replicates of 25 seeds. 
Tabela 3. Porcentagem (PG), índice de velocidade (IVG) e tempo médio (TMG) de germinação de sementes de Acacia polyphylla (monjoleiro) a $25^{\circ} \mathrm{C}$, submetidas a diferentes fotoperíodos de luz branca iniciados e finalizados com luz de sombreamento. Médias seguidas de mesma letra, em cada coluna, não diferem entre si pelo teste de Tukey, a 5\% de probabilidade.

Table 3. Germination percentage (PG), speed index (IVG) and mean germination time (TMG) of Acacia polyphylla ("monjoleiro") seeds at $25^{\circ} \mathrm{C}$, submitted to different photoperiods of white light initiated and concluded with shade light. Means for each column followed by same letter are not significantly different $(\mathrm{P}>0.05)$.

\begin{tabular}{|c|c|c|c|c|c|}
\hline \multicolumn{3}{|c|}{ Fotoperíodo (horas) } & \multirow{2}{*}{$\begin{array}{l}\mathrm{PG} \\
\%\end{array}$} & \multirow[t]{2}{*}{ IVG } & \multirow{2}{*}{$\begin{array}{l}\text { TMG } \\
\text { (dias) }\end{array}$} \\
\hline Sombreamento & Branca & Sombreamento & & & \\
\hline $1 / 4$ & 12 & $1 / 4$ & 72,9 a & $1,6 \mathrm{a}$ & $12,5 \mathrm{a}$ \\
\hline 2 & 8 & 2 & $78,0 \mathrm{a}$ & $1,7 \mathrm{a}$ & $12,5 \mathrm{a}$ \\
\hline 3 & 6 & 3 & $64,5 \mathrm{a}$ & $1,5 \mathrm{a}$ & $12,8 \mathrm{a}$ \\
\hline 4 & 4 & 4 & $79,8 \mathrm{a}$ & $1,6 \mathrm{a}$ & $13,8 \mathrm{a}$ \\
\hline 5 & 2 & 5 & $80,8 \mathrm{a}$ & $1,9 \mathrm{a}$ & $11,8 \mathrm{a}$ \\
\hline 0 & 0 & 0 & $18,3 \mathrm{~b}$ & $0,5 \mathrm{~b}$ & $18,0 \mathrm{~b}$ \\
\hline \multicolumn{3}{|c|}{ Coeficiente de variação (\%) } & 15,0 & 21,7 & 13,5 \\
\hline
\end{tabular}

sementes de monjoleiro, contudo, a presença de luz, independentemente da qualidade, foi o fator que mais influenciou no processo germinativo. Esse tipo de resposta corresponde à de fluência muito baixa (RFMB), necessitando, para tal, um fotoequilíbrio do fitocromo muito baixo, como mencionado por Mancinelli (1994).

Esse comportamento difere daquele apresentado por muitas espécies pertencentes aos estádios iniciais da sucessão, em que as luzes vermelha e vermelhaextrema têm, respectivamente, promovido e inibido a germinação de suas sementes. Como exemplo podem ser citadas as sementes de Urera caracasana (Jacq.) Griseb. (Orozco-Segovia et al. 1987), Piper aequale Vahl., P. umbellatum L., P. auritum H.B.K. e P. hispidum Sw. (Orozco-Segovia \& Vázquez-Yanes 1989).

Agradecimentos - Os autores agradecem ao suporte financeiro da Fapesp (bolsa de doutorado do primeiro autor e auxílio à pesquisa) e ao $\mathrm{CNPq}$ (bolsa de pesquisador do segundo autor).

\section{Referências bibliográficas}

ARAÚJO NETO, J.C. \& AGUIAR, I.B. 2000. Germinative pretreatments to dormancy break in Guazuma ulmifolia Lam. seeds. Scientia Forestalis 58:15-24.

BANZATTO, D.A. \& KRONKA, S.N. 1992. Experimentação agrícola. $2^{a}$ ed. Funep, Jaboticabal.

BAROLI, A.A. 1998. Germinação de sementes de Baccharis dracunculifolia DC., Eupatorium laevigatum Lam. e Galinsoga parviflora Cav. (Asteraceae). Tese de doutorado, Universidade Estadual Paulista, Rio Claro.
BEWLEY, J.D. \& BLACK, M. 1982. Physiology and biochemistry of seeds in relation to germination. Springer-Verlag, New York.

BEWLEY, J.D. \& BLACK, M. 1985. Seeds: physiology of development and germination. Plenum Press, New York.

BORGES, E.E.L. \& RENA, A.B. 1993. Germinação de sementes. In Sementes florestais tropicais (I.B. Aguiar, F.C.M. Piña-Rodrigues \& M.B. Figliolia, eds.). Abrates, Brasília, p.83-135.

BRASIL. 1992. Ministério da Agricultura e Reforma Agrária. Regras para análise de sementes. SNDA/DNDV/CLAV, Brasília.

BRYANT, J.A. 1985. Fisiologia da semente. EPU, São Paulo.

CARVALHO, N.M. \& NAKAGAWA, J. 1988. Sementes: ciência, tecnologia e produção. $3^{a}$ ed. Fundação Cargill, Campinas.

CASAL, J.J. \& SÁNCHEZ, R.A. 1998. Phytochromes and seed germination. Seed Science Research 8:317-329.

CASAL, J.J., SÁNCHEZ, R.A. \& BOTTO, J.F. 1998. Modes of action of phytochromes. Journal of Experimental Botany 49:127-138.

CASTELLANI, E.D. \& AGUIAR, I.B. 1998. Condições preliminares para a germinação de sementes de candiúba (Trema micrantha (L.) Blume). Revista Brasileira de Engenharia Agrícola e Ambiental 2:80-83.

CORRÊA, M.P. 1978. Dicionário de plantas úteis do Brasil e das exóticas cultivadas. Imprensa Nacional, Rio de Janeiro.

GOMES, S.M.S. \& BRUNO, R.L.A. 1992. Influência da temperatura e substratos na germinação de sementes de urucum (Bixa orellana L.). Revista Brasileira de Sementes 14:47-50.

LABOURIAU, L.G. 1983. A germinação das sementes. Secretaria Geral da OEA, Washington. 
LABOURIAU, L.G. \& VALADARES, M.E.B. 1976. On the germination of seeds of Calotropis procera (Ait.) Ait.f. Anais da Academia Brasileira de Ciências 48:263-284.

LAGÔA, A.M.M.A. \& PEREIRA, M.F.D.A. 1987. Fotoblastismo em sementes de Ricinus communis L. Revista Brasileira de Botânica 10:155-158.

LEAL FILHO, N. \& BORGES, E.E.L. 1992. Influência da temperatura e da luz na germinação de sementes de canudo de pito (Mabea fistulifera Mart.). Revista Brasileira de Sementes 14:57-60.

LEITE, I.T.A. 1998. Aspectos fisiológicos da germinação de sementes de Miconia cinnamomifolia (DC.) Naud.Melastomataceae. Tese de doutorado, Universidade Estadual Paulista, Rio Claro.

LORENZI, H. 1992. Árvores brasileiras: manual de identificação e cultivo de plantas arbóreas nativas do Brasil. Editora Plantarum, Nova Odessa.

MANCINELLI, A.L. 1994. The physiology of phytochrome action. In Photomorphogenesis in plants (R.E. Kendrick \& G.H.M. Kronenberg, eds.). $2^{\text {nd }}$ ed. Kluwer Academic Publishers, Dordrecht, p.211-269.

NAKAGAWA, J. 1994. Testes de vigor baseados na avaliação das plântulas. In Testes de vigor em sementes (R.D. Vieira \& N.M. Carvalho, eds.). Funep, Jaboticabal, p.49-85.

OKUSANYA, O.T. 1978. The effects of light and temperature on germination and growth of Luffa aegyptiaca. Physiologia Plantarum 44:429-433.

OKUSANYA, O.T. 1980. Germination and growth of Celosia cristata L., under various light and temperature regimes. American Journal of Botany 67:854-858.

OROZCO-SEGOVIA, A., VÁZQUEZ-YANES, C., COATES-ESTRADA, R. \& PÉREZ-NASSER, N. 1987. Ecophysiological characteristics of the seed of the tropical forest pioneer Urera caracasana (Jacq.) GrisebUrticaceae. Tree Physiology 3:375-386.

OROZCO-SEGOVIA, A. \& VÁZQUEZ-YANES, C. 1989. Light effect on seed germination in Piper L. Ecologia Plantarum 10:123-146.
PEREZ, S.C.J.G.A. \& MORAES, J.A.P.V. 1990. Influências da temperatura, da interação temperatura-giberelina e do estresse térmico na germinação de Prosopis juliflora (Sw.) DC. Revista Brasileira de Fisiologia Vegetal 2:41-53.

PONS, T.L. 1993. Seed responses to light. In Seeds: the ecology of regeneration in plant communities (M. Fenner, ed.). CAB International, Wallingford, p.259-284.

RANDI, A.M. \& FELIPPE, G.M. 1981. Efeito da temperatura, luz e reguladores de crescimento na germinação de Stevia rebaudiana Bert. Ciência e Cultura 33:404-411.

TAIZ, L. \& ZEIGER, E. 1998. Plant physiology. $2^{\text {nd }}$ ed. Sinauer Associates, Sunderland.

VÁZQUEZ-YANES, C. \& OROZCO-SEGOVIA, A. 1984. Fisiología ecológica de las semillas de árboles de la selva tropical: un reflejo de su ambiente. Ciencia 35:191-201.

VÁZQUEZ-YANES, C. \& OROZCO-SEGOVIA, A. 1987. Fisiología ecológica de semillas en la Estación de Biologia Tropical "Los Tuxtlas", Veracruz, México. Revista de Biologia Tropical 35:85-96.

VÁZQUEZ-YANES, C. \& OROZCO-SEGOVIA, A. 1990. Ecological significance of light controlled seed germination in two contrasting tropical habitats. Oecologia 83:171-175.

VÁZQUEZ-YANES, C. \& OROZCO-SEGOVIA, A. 1991. Seed viability, longevity and dormancy in a tropical rain forest. In Anais do II Simpósio Brasileiro sobre Tecnologia de Sementes Florestais (M.B. Figliolia, coord.). Instituto Florestal, São Paulo, p.175-196.

VENTURA, A., BERENGUT, G. \& VICTOR, M.A.M. 1965/ 1966. Características edafo-climáticas das dependências do Serviço Florestal do Estado de São Paulo. Silvicultura em São Paulo 4/5:57-140.

VIDAVER, W. 1980. Light and seed germination. In The physiology and biochemistry of seed dormancy and germination (A.A. Khan, ed.). North-Holland Publishing Company, New York, p.181-192. 